PAEDAGOGIA ChristianA

2/24 (2009) - ISSN 1505-6872

Renata Ernst-Milerska*

Warszawa

\title{
Kontekst migracyjny jako czynnik różnicujący osiągnięcia szkolne uczniów w Niemczech
}

Wyniki badań PISA, realizowanych w krajach z wysokim odsetkiem migrantów, wskazują, że pochodzenie migracyjne stanowi czynnik warunkujący osiagnięcia szkolne uczniów. Na szczególną uwagę zasługuje sytuacja w Niemczech. W państwie tym uczniowie-migranci osiagali bowiem zdecydowanie niższe wartości w zakresie kompetencji matematycznych, przyrodniczych i rozumienia tekstu aniżeli ich rówieśnicy bez kontekstu migracyjnego. Utrwalenie takiej sytuacji może skutkować w przyszłości gorszymi perspektywami zawodowymi i społecznymi, a tym samym - pogłębianiem nierówności społecznych. Z tego też względu analiza czynników warunkujących efektywność kształcenia ma nie tylko wymiar teoretyczny, lecz również stanowi przyczynek do kształtowania praktyki oświatowej ${ }^{1}$.

\section{Pojęcie kontekstu migracyjnego}

Podejmując kwestię analizy osiągnięć szkolnych uczniów migrantów, należy zdefiniować kryterium przynależności do tej grupy społecznej. Wydaje się ChAT.

* Dr Renata Ernst-Milerska, adiunkt w Katedrze Podstawowych Problemów Wychowania

' PISA 2000. Basiskompetenzen von Schülerinnen und Schülern im internationalen Vergleich, Deutsches PISA-Konsortium, Opladen 2001; PISA 2003. Der Bildungsstand der Jugendlichen in Deutschland - Ergebnisse des zweiten internationalen Vergleichs, PISA-Konsortium Deutschland, Münster 2004; PISA 2006. Die Ergebnisse der dritten internationalen Vergleichstudie, PISA-Konsortium Deutschland, Münster 2007. Por. także: Bildung in Deutschland. Ein indikatorengestützter Bericht mit einer Analyse zu Bildung und Migration, Konsortium Bildungsberichterstattung, Bielefeld 2006. W kontekście europejskim problematyka integracji uczniów-migrantów została omówiona m.in. w: Integrating Immigrant Children into Schools in Europe, Directorate-General for Education and Culture, European Commission, Eurydice, Brussels 2004. 
bowiem konieczne uwzględnienie nie tylko uczniów, którzy nie mają obywatelstwa kraju osiedlenia, lecz również tych, którzy - posiadając doświadczenie migracyjne - zamieszkują ten kraj w kolejnym pokoleniu. Aby oddać szerokie rozumienie przynależności migracyjnej, w badaniach PISA wprowadzono pojęcie „kontekst migracyjny”. Po pierwsze, wskazuje ono na historyczną ciagłość jednostkowych biografii. Doświadczenie migracji, które dotyczyło określonego pokolenia (rodziców, dziadków), ma bowiem swoją kontynuację w życiu uczniów pochodzących z takich rodzin. Otwarte pozostaje natomiast pytanie, jak daleko w przeszłość mogą sięgać korzenie takiego doświadczenia. Po drugie, z migracją związany jest także określony kontekst społeczno-kulturowy, w którym dzieci są wychowywane i dorastają. Odnosi się to zarówno do obyczaju i etosu, jak i co z perspektywy kształcenia wydaje się najważniejsze - do języka. Warunkiem sukcesu edukacyjnego i integracji społecznej jest bowiem opanowanie języka kraju osiedlenia migrantów. $Z$ tego też względu w badaniach PISA próbowano zdiagnozować pochodzenie ucznia nie tylko za pomocą pytań dotyczących miejsca urodzenia jego i jego rodziców, lecz również tego, czy w swojej rodzinie komunikuje się w języku, w którym odbywają się zajęcia lekcyjne. Z perspektywy kryterium kontekstu migracyjnego można wyróżnić 4 grupy uczniów. Pierwszą stanowią uczniowie bez kontekstu migracyjnego, których rodzice i oni sami urodzili się i są zakorzenieni w kulturze kraju, w którym odbyło się badanie testowe. Pozostałe grupy tworzą uczniowie z tzw. kontekstem migracyjnym. Do drugiej zaliczają się uczniowie, w przypadku których jeden z rodziców urodził się w kraju objętym badaniem, drugi natomiast za granica. Trzecia grupa obejmuje młodzież, która urodziła się na obszarze badanego kraju, natomiast ich rodzice za granicą. Ostatnią grupę stanowią uczniowie tzw. pierwszej generacji, którzy sami, jak i ich rodzice, urodzili się poza granicami badanego kraju².

\section{Uczniowie z kontekstem migracyjnym - charakterystyka zjawiska}

W 2005 opracowano w Niemczech Mikrozensus, dokument, dzięki któremu udało się uzyskać reprezentatywne dane odnoszące się do pochodzenia, miejsca urodzenia, czasu przybycia oraz uzyskania obywatelstwa. Możliwe stało się również zdefiniowanie i zróżnicowanie migrantów zgodnie z ich indywidualnymi i rodzinnymi doświadczeniami migracyjnymi. Przyjęcie szerokiego kryterium przynależności migracyjnej zmieniło szacunki dotyczące skali zjawiska. Zgodnie z dotychczasowymi danymi, np. Federalnego Urzędu Statystycznego, liczbę migrantów określano na ok. 7,3 miliona osób, co stanowiło 8,8\% ogółu ludności. Tymczasem według danych zawartych w Mikrozensus 15,3 miliona mieszkańców Niemiec cechuje się indywidualnym bądź rodzinnym (co najmniej jeden

${ }^{2}$ G. Ramm, M. Prezel i inni, Soziokulturelle Herkunft: Migration, w: PISA 2003. Der Bildungsstand, s. 255-256; Bildung in Deutschland, s. 345. 
z rodziców) doświadczeniem migracyjnym, co sprawia, że osoby z kontekstem migracyjnym stanowią prawie jedną piątą $(18,6 \%)$ niemieckiego społeczeństwa ${ }^{3}$. Należy zarazem pamiętać, że odsetek tych osób nie rozkłada się równomiernie na terenie całej Republiki Federalnej, lecz jest istotnie wyższy w jej części zachodniej, a więc w tzw. starych krajach związkowych.

Dla systemu kształcenia szczególnie istotna jest grupa wiekowa poniżej 25 roku życia. Dane pokazuja, że w tej grupie ponad jedna czwarta osób $(27,2 \%)$, czyli około 6 milionów młodych Niemców, posiada kontekst migracyjny. Należy stwierdzić, że wśród dzieci i młodzieży występuje duży udział migrantów z Turcji (ok. 7\% w poszczególnych grupach wiekowych). Pozostałe osoby pochodzą głównie z krajów związanych z migracją zarobkową lub z pozostałych krajów „starej” unii europejskiej. Odsetek młodzieży z kontekstem migracyjnym rozkłada się bardzo nierównomiernie w odniesieniu do poszczególnych krajów związkowych i miast. Przykładowo, w 2005 roku udział młodych ludzi z kontekstem migracyjnym w populacji rówieśników w Hamburgu i Bremie wynosił 40\%, a w Badenii-Würtembrgii, Berlinie, Hesji i Nadrenii-Westfalii ponad 33\% ${ }^{4}$.

Charakterystyka populacji dzieci i młodzieży dowodzi, że kwestia kontekstu migracyjnego odnosi się do wszystkich poziomów kształcenia. W 2005 w grupie 6-latków rozpoczynających edukację szkolną ponad 30 dzieci na 100 (ponad $30 \%$ ) posiadało kontekst migracyjny. W kolejnych grupach wiekowych (6 do 10 lat, 10 do 16 oraz 16 do 25 lat) proporcje były porównywalne. Odsetek młodych Niemców z kontekstem migracyjnym wahał się od $24 \%$ do $29 \%$. W wyższych grupach wiekowych, zwłaszcza powyżej 45 roku życia, procent osób z kontekstem migracyjnym był natomiast o połowę mniejszy ${ }^{5}$. Powyższe dane pokazuja, że doświadczenie migracyjne jest bardziej upowszechnione w młodszej części społeczeństwa. Szczególnie ważnym wyzwaniem jest integracja dzieci i młodzieży w ramach systemu edukacyjnego. Trudności w tym zakresie są spowodowane heterogenicznością populacji migracyjnej ze względu na status, czas osiedlenia się w Niemczech, jak również przynależność etniczną.

\section{Kompetencje uczniów z kontekstem migracyjnym}

Badania PISA były przeprowadzone w Niemczech, podobnie jak w innych krajach, w trzech edycjach $(2000,2003,2006)$ i dotyczyły osiagnięć szkolnych uczniów 15-letnich w zakresie kompetencji matematycznych, przyrodniczych i rozumienia tekstu. We wszystkich edycjach ujawniły się statystycznie istotne

${ }^{3}$ Bildung in Deutschland, s. 139; O. Walter, P. Taskinen, Kompetenzen und bildungsrelevante Einstellungen von Jugendlichen mit Migrationshintergrundin Deutschland: Ein Vergleich mit ausgewählten OECD-Staaten, w: PISA 2006. Die Ergebnisse, s. 346.

${ }^{4}$ Bildung in Deutschland, s. 143.

5 Tamże, s. 143. 
różnice pomiędzy wynikami młodzieży z kontekstem migracyjnym i bez kontekstu migracyjnego. Pisząc o młodzieży z kontekstem migracyjnym, należy pamiętać, że nie jest to grupa jednolita. Jak zostało to opisane w punkcie dotyczącym pojęcia kontekstu migracyjnego, w analizie wyników badań PISA wyróżnia się obok młodzieży bez kontekstu migracyjnego dodatkowo trzy grupy młodzieży z kontekstem migracyjnym. Przeciętnie najmniejszą różnicę w stosunku do „młodzieży tuziemskiej” wykazuje grupa, w której jeden z rodziców był urodzony za granica, a największe różnice odnoszą się do tak zwanego drugiego pokolenia. Różnice w osiaganych kompetencjach pomiędzy poszczególnymi grupami są zbliżone: wynoszą one od 36 do 93 punktów w odniesieniu do kompetencji przyrodniczych, od 28 do 81 punktów w czytaniu ze zrozumieniem i od 29 do 77 punktów w zakresie kompetencji matematycznych. Dysproporcje w rozumieniu tekstu i matematyce są więc mniejsze niż w naukach przyrodniczych ${ }^{6}$. Najbardziej zaskakującym jest jednak fakt, że poziom kompetencji młodzieży przebywającej w Niemczech w drugim pokoleniu jest we wszystkich obszarach niższy niż poziom kompetencji młodzieży w pierwszym pokoleniu.

W porównaniu kompetencji czytania ze zrozumieniem wyniki osiagane przez uczniów z kontekstem migracyjnym wskazują na nieznaczące różnice pomiędzy uczniami pochodzącymi z rodzin, w których oboje rodzice urodzili się w Republice Federalnej, a pochodzącymi z tzw. małżeństw mieszanych, w których jeden z rodziców urodził się poza obszarem Niemiec, a drugi w Niemczech. Zupełnie inna sytuacja występuje w przypadku uczniów w drugim pokoleniu, pochodzących z rodzin, w których obydwoje rodzice urodzili się poza granicami Niemiec. Prawie 50\% uczniów z tej grupy migrantów nie osiagnęło w czytaniu elementarnego poziomu pierwszego, mimo że $70 \%$ z nich całą swoją edukację odbyło w szkołach niemieckich. Udział ekstremalnie słabych uczniów wzrasta w tej grupie do $20 \%$. W grupie uczniów, w przypadku których obydwoje rodzice imigrowali do Niemiec, bardzo dobrą znajomość języka niemieckiego i umiejętność radzenia sobie z trudnym tekstami wykazuje tylko $2 \%$ badanych. Deficyty w kompetencji czytania ze zrozumieniem mają swoje dalsze konsekwencje w innych badanych obszarach ${ }^{7}$.

Podobnie rozkładają się wyniki dotyczące kompetencji przyrodniczych. W Niemczech, w stosunku do innych badanych państw, stwierdza się największe dysproporcje $\mathrm{w}$ tym zakresie pomiędzy młodzieżą $\mathrm{z}$ kontekstem migracyjnym a uczniami bez kontekstu migracyjnego. Należy jednak zauważyć, że w przypadku młodzieży przebywającej w Niemczech w pierwszym pokoleniu dysproporcje w stosunku do młodzieży bez kontekstu migracyjnego są mniejsze aniżeli w pozostałych grupach uczniów z kontekstem migracyjnym. Lepsze wyniki uczniów migrantów w pierwszym pokoleniu mogą mieć związek z dość wysokim udzia-

${ }^{6}$ O. Walter, P. Taskinen, dz. cyt., s. 349.

7 J. Baumert, G. Schümer, Familiäre Lebensverhältnisse, Bildungsbeteiligung und Kompetenzerwerb, w: PISA 2000. Basiskompetenzen, s. 375-379. 
łem w tej grupie młodzieży tzw. późnych przesiedleńców, którzy charakteryzowali się stosunkowo dobrą znajomością języka niemieckiego.

Interesujące wydaje się porównanie wyników młodzieży pochodzenia tureckiego i młodzieży przybyłej z dawnego Związku Radzieckiego. W badaniu PISA 2003 kompetencje matematyczne młodzieży pochodzenia tureckiego ze średnim rezultatem 411 punktów plasowały się znacząco poniżej średniej całościowej. Grupa młodzieży pochodzącej z byłego Związku Radzieckiego uzyskała natomiast średnio 466 punktów. Różnicy tej nie można tłumaczyć czynnikami społecznymi i gospodarczymi, ponieważ średnia wartość sytuacji społeczno-ekonomicznej (wskaźnik HISEI) obu grup była porównywalna (Turcja - 36; dawny Związek Radziecki - 40) ${ }^{8}$. Szczególnie alarmujący jest fakt, że ponad 50\% młodzieży pochodzenia tureckiego (30\% - w przypadku młodzieży pochodzącej z byłego Związku Radzieckiego) uzyskuje marginalne kompetencje, które nie wykraczają poza poziom pierwszy ${ }^{9}$. Młodzież ta doświadczyła porażki w obszarze szkolnym, co w przyszłości może okazać się decydujące w odniesieniu do ich dalszej drogi edukacyjnej i zawodowej, a w konsekwencji do sposobu uczestnictwa w życiu społecznym.

\section{Uwarunkowania społeczne i językowe}

Wyniki uzyskane w badaniach PISA pokazują, że różnice w kompetencjach pomiędzy młodzieżą z kontekstem migracyjnym i bez kontekstu migracyjnego są w dużej mierze pochodną statusu społecznego i poziomu opanowania języka. W odniesieniu do statusu społecznego uwzględniono trzy wskaźniki: sytuację społeczno-ekonomiczna, na podstawie wskaźnika HISEI, dostępność dóbr kultury oraz poziom wykształcenia rodziców.

Analiza wyników badań PISA dowodzi, że czynnik społeczno-ekonomiczny ma znaczenie dla rozwoju kompetencji edukacyjnych. Badani uczniowie zostali przyporządkowani do czterech grup - ćwiartek (1-25\%, 26-50\%, 51-75\%, 76-100\%), ze względu na poziom wykształcenia, majętności i prestiżu wykonywanego zawodu. Wyniki ukazały istniejące dysproporcje w zakresie statusu społecznego. Okazało się, że o ile uczniowie z rodzin bez kontekstu migracyjnego lub z rodzin, w których tylko jeden z rodziców urodził się za granica, rzadko plasowali się w dolnej ćwiartce, o tyle pozostali uczniowie z kontekstem migracyjnym w ponad $60 \%$ uplasowali się w najniższej ćwiartce. Powyższe po-

${ }^{8}$ G. Ramm, M. Prezel i inni, dz. cyt., s. 264-265.

9 Przyczyna leży być może również w tym, że ludność turecka z różnych przyczyn dąży do tworzenia zamkniętych, etnicznych społeczności. Zarazem jest na tyle dużą wspólnotą że może budować własną relatywnie mocną infrastrukturę ekonomiczną i kulturową. Pozwala to tworzyć stabilną kulturę migracyjną pomiędzy kulturą kraju pochodzenia a kulturą kraju osiedlenia się. Por. J. Baumert, G. Schümer, dz. cyt., s. 344. 
twierdza, że rodzice mający doświadczenie migracyjne, w przeciwieństwie do „tuziemców”, w większości przypadków wykonują w Niemczech zawody niżej oceniane społecznie. Prawie dwie trzecie osób urodzonych poza Republiką Federalną pracuje w Niemczech jako zwykli pracownicy, z czego połowa wykonuje czynności przyuczające do zawodu. Taki stan rzeczy przekłada się w konsekwencji na wysokość gratyfikacji i standard życia tej grupy społecznej ${ }^{10}$.

Analizując poziom wykształcenia rodziców, ukończenie przynajmniej szkoły zawodowej, szkoły realnej, wyższej szkoły zawodowej bądź szkoły kończącej się maturą zadeklarowało 40\% rodziców uczniów, którzy w pierwszym pokoleniu urodzili się w Niemczech. Dla porównania, w przypadku rodzin bez kontekstu migracyjnego bądź z jednym rodzicem urodzonym za granicą współczynnik ten wyniósł ponad $80 \%$.

Status społeczny uczniów z kontekstem migracyjnym staje się także istotnym czynnikiem warunkującym wybór typu szkoły. Uczniowie ci znacznie częściej wybierają podstawowe formy kształcenia. W przypadku młodzieży, której obydwoje rodzicie imigrowali do Niemiec, uczęszczanie do wybranego typu szkoły odpowiada strukturze z lat 70. XX wieku - prawie 50\% uczniów uczęszcza do szkoły głównej (Hauptschule), a jedynie ok. 15\% do gimnazjów. Prawie co drugi uczeń z tureckim kontekstem migracyjnym uczęszcza do szkoły głównej, a tylko co ósmy do gimnazjum. W przypadku uczniów z innych krajów związanych z migracją zarobkową jedna trzecia uczęszcza do szkoły, a jedna czwarta do gimnazjum. W szkołach, w których odsetek migrantów wynosi ponad połowę, koncentruje się młodzież, która w swoich domach nie mówi w języku niemieckim. Szkoła główna jest typem szkoły najczęściej wybieranym przez migrantów. Ponieważ najwyższy odsetek migrantów wykazywany jest w dużych miastach, to $\mathrm{w}$ konsekwencji młodzież z kontekstem migracyjnym stanowi w takich szkołach większość społeczności uczniowskiej (np. 1998 we Frankfurcie nad Menem odsetek ten wynosił $62,6 \%)^{11}$. Koncentracja młodzieży z kontekstem migracyjnym w placówkach określonego typu wiążę się z jeszcze jedną negatywną konsekwencją. A mianowicie w szkołach, w których odsetek młodzieży obcojęzycznej przekracza 20\%, osiagnięcia uczniów z kontekstem migracyjnym wykazują tendencję spadkową (odwrotnie niż w szkołach, w których udział uczniów z kontekstem migracyjnym wynosi do $5 \%$ ).

$\mathrm{Z}$ perspektywy teorii integracyjnych, które decydującą rolę w zakresie sukcesu integracyjnego przypisują opanowaniu i używaniu języka docelowego kraju migracji, można przypuszczać, że integracja migrantów przebiega lepiej i szyb-

${ }^{10}$ Tamże, s. 345-346; G. Pommerin-Götze, Zur Bildungssituation Jugendlicher mit Migrationshintergrund, w: V. Frederking, H. Heller, A. Scheunpflug (red.), Nach PISA. Konsequenzen für Schule und Lehrerbildung nach zwei Studien, Wiesbaden 2005, s. 146-147.

${ }^{11}$ J. Baumert, G. Schümer, dz. cyt., s. 373; Bildung in Deutschland, s. 151; Y. KarakasogluAydin, Kinder aus Zuwandererfamilien im Bildungssystem, w: W. Böttcher, K. Klemm, T. Rauschenbach (red.), Bildung und Soziales in Zahlen, München 2001, s. 277. 
ciej w tych przypadkach, w których język rodzimy migrantów pokrywa się z językiem urzędowym bądź językiem komunikacji kraju osiedlenia. Powyższe nie odnosi się do sytuacji w Niemczech. W przypadku tego kraju migranci pochodzą bowiem w zdecydowanej większości z rodzin i państw, dla których język niemiecki jest językiem obcym. Należy jednak stwierdzić, że zdecydowana większość uczniów z kontekstem migracyjnym urodziła się w Niemczech. Młodzież, która przybyła wraz ze swoimi rodzicami do Niemiec, stanowi 8,5\%. Przybyli oni w bardzo różnych momentach edukacji szkolnej. Większa część (57,3\%) przybyła przed szóstym rokiem życia. Dalsze 27,6\% w okresie szkoły podstawowej, a $15,1 \%$ dopiero w późniejszym okresie. Przybyłe ostatnio rodziny w połowie pochodzą z krajów byłego Związku Radzieckiego.

Jeżeli chodzi o używanie języka niemieckiego przez uczniów z kontekstem migracyjnym, to odsetek młodzieży, która w swoich rodzinach mówi w języku niemieckim, wyniósł w badaniach z 2006 roku 55,8\%, porównywalnie z wynikiem z roku 2000 (w 2003 był wyższy - 63,8). Powyższe oznacza, że duża część uczniów z kontekstem migracyjnym ciągle jako narzędzia podstawowej komunikacji w rodzinie używa języka innego niż niemiecki. Oznacza to, że przynajmniej dla części z nich język niemiecki pozostaje drugim językiem - językiem obcym. Uczniowie tacy mogą mieć istotne trudności w rozumieniu zajęć szkolnych. Studia PISA potwierdziły, że uczniowie, których język potoczny odbiegał od języka zajęć szkolnych, uzyskali niższe wyniki w zakresie badanych kompetencji. Innymi słowy, uczniowie, którzy w domach nie mówią w języku niemieckim, rozwijają znacząco niższe kompetencje niż ci, dla których język niemiecki jest podstawowym medium komunikacji. Braki w umiejętnościach językowych stanowią najważniejsza barierę w edukacji szkolnej. Cechą szkolnictwa niemieckiego jest bowiem bardzo szybka segregacja uczniów ze względu na typ szkoły, dokonująca się w zależności od kraju związkowego już po czwartej bądź szóstej klasie. Dlatego też szczególnego znaczenia nabiera integracja edukacyjna uczniów do dziesiątego roku życia ${ }^{12}$.

\section{Konkluzje}

W państwach o wysokim odsetku migrantów od pewnego czasu zwraca się szczególną uwagę na - warunkowane kontekstem migracyjnym - dysproporcje pomiędzy osiagnnięciami szkolnymi uczniów. Należy jednak podkreślić, że migracja nie zawsze musi wiązać się z niższymi kompetencjami w najważniejszych obszarach kształcenia. Otóż młodzież w Australii, Nowej Zelandii, Wielkiej Brytanii posiada przeciętnie zbliżony poziom kompetencji do młodzieży bez kontekstu migracyjnego. W Niemczech natomiast wykazano największe zróżnicowanie w tym zakresie. Niekiedy wręcz mówi się o porażce edukacyjnej. Problem polega

${ }^{12}$ J. Baumert, G. Schümer, dz. cyt., s. 374, 394nn; G. Pommerin-Götze, dz. cyt., s. 152. 
bowiem na tym, że większość uczniów z kontekstem migracyjnym od urodzenia wzrastała i kształciła się w niemieckich instytucjach oświatowych. Testy międzynarodowej oceny umiejętności uczniów PISA 2000, 2003 oraz 2006 wykazały, że uczniowie niemieccy z kontekstem migracyjnym wykazują niższe kompetencje w rozumieniu tekstu, w umiejętnościach matematycznych i przyrodniczych niż młodzież bez kontekstu migracyjnego. W kategoriach społecznych takie zróżnicowanie edukacyjne skutkuje gorszą perspektywą odniesienia sukcesu społecznego i finansowego w przyszłości.

Jak zostało to opisane powyżej, wyniki badań wskazują na istotne znaczenie statusu społecznego oraz poziomu opanowania języka. Okazuje się bowiem, że młodzież, która wzrasta w domach o wyższym statusie społecznym i gdzie językiem komunikacji jest język niemiecki, reprezentuje kompetencje na poziomie porównywalnie wysokim bądź tylko niewiele niższym niż młodzież bez kontekstu migracyjnego. Przykładem takiej grupy są uczniowie, których tylko jeden z rodziców urodził się za granica. Najbardziej zaskakujące jest jednak stwierdzenie, że przeciętne kompetencje uczniów urodzonych w Republice Federalnej (tak zwane drugie pokolenie) były niższe od kompetencji uczniów, którzy dopiero przybyli do Niemiec ze swoimi rodzicami (tak zwane pierwsze pokolenie). Może to świadczyć o swoistej porażce funkcjonowania migrantów w niemieckim systemie edukacji. Taki stan rzeczy dziwi tym bardziej, że w Niemczech idee edukacji międzykulturowej próbuje się wcielać w życie od początku lat 80. XX wieku. Należy również pamiętać, że edukacja w Niemczech jest oparta na solidnych podstawach finansowych $(6 \% \mathrm{PKB} \text { - ca. } 134 \text { miliardy euro })^{13}$.

W obecnie toczonej debacie pedagogicznej podkreśla się, że konieczne staje się postrzeganie migracji nie tylko jako problemu, lecz również szansy dla społeczeństwa niemieckiego. Kulturowa i społeczna heterogeniczność populacji migrantów może bowiem stanowić istotny potencjał rozwojowy. W obszarze polityki i nauki istnieje zgoda co do tego, że wychowanie, kształcenie i system kwalifikacyjny stanowią funkcję kluczową. Szczególnie w obliczu rozwoju demograficznego ogromne znaczenie przypisuje się wspieraniu kształcenia i wykształcenia młodych migrantów, gwarantujących w przyszłości rozwój gospodarczy kraju.

Planowane działania w zakresie oświaty i polityki społecznej powinny zostać skierowane na przedsięwzięcia służące zmniejszeniu zależności pomiędzy statusem społecznym i materialnym uczniów a ich wynikami w nauce oraz na wspieraniu kształcenia dzieci z rodzin migrantów, zwłaszcza w aspekcie nauki języka niemieckiego. Coraz częściej zwraca się uwagę na wspieranie uczniów

${ }^{13}$ J. Baumert, G. Schümer, dz. cyt, s. 346. Prawie połowa piętnastolatków, których ojcowie urodzili się poza Republiką Federalną, sama urodziła się już w Niemczech. Prawie $70 \%$ tej młodzieży uczęszczała przez cały czas swojej obowiązkowej edukacji do placówek oświatowych w Niemczech. Analiza wyników kompetencji czytania ze zrozumieniem w roku 2000 może więc postawić znak zapytania odnośnie do efektów kształcenia. 
na etapie edukacji wczesnoszkolnej. Jak pokazują dane, niepowodzenia szkolne w dużym stopniu tam mają swój początek. W klasach 1-3 ryzyko powtarzania klasy w przypadku dzieci z kontekstem migracyjnym jest czterokrotnie wyższe niż w przypadku dzieci rdzennie niemieckich ${ }^{14}$. W Niemczech zauważalne jest także silne powiązanie segregacji społecznej i etnicznej. Odsetek migrantów w szkole idzie $\mathrm{w}$ parze $\mathrm{z}$ odsetkiem uczniów pochodzących $\mathrm{z}$ rodzin o niskim statusie społecznym. Dla przykładu można dokonać zestawienia dwóch typów szkół. W gimnazjum mamy do czynienia z najniższym odsetkiem migrantów, a zarazem z uczniami, których rodzice cechują się wysokim statusem społecznym. W przeciwieństwie do tego, szkoły główne (Hauptschule) charakteryzują się niskim statusem społecznym uczniów i ich rodziców, a zarazem wysokim udziałem uczniów z kontekstem migracyjnym.

\section{Migration context as the determining factor of school achievements (Summary)}

Migration is not only the social but also the educational problem. This article is concerned on the migration in Germany and on its influence on the school achievements. At first we have to explain the scale of migration among students population. According to the data of the Federal Statistical Department in Germany (Statistisches Bundesamt) the level of the migrants equals 7.3 million people, it gives $8.8 \%$ of German population. The problem is that this number does not concern the people who live in Germany in next generation and still belong to primary origin culture. This group of people is German citizens but their identity is still constructed by the migration patterns and habits. The meaning of migration context (Migrationshintergrund) was created to describe it. "Mikrozensus" paper (2005) estimated the population of migrants used the meaning of migration context. According to this estimation the level of people with migration context equals 15.3 million, it gives $18.6 \%$ of the whole population living in Germany. The number of this indicator rises in the population of people under 25 to $27 \%$ and in some cities as Hamburg or Bremen to $40 \%$. According to three editions of PISA studies the migration context is the main determining factor of school achievements in every researched competences - in reading, mathematical and scientific literacy. It leads to the marginalisation of migrants students in the future. In the second part of article the relationship between the migration and school achievements is interpreted. Analyses show the most important phenomena which must be concluded in educational school system.

${ }^{14}$ Bildung in Deutschland, s. 152. 